Article

\title{
Crystal Growth and Luminescence Properties of $\mathrm{Dy}^{3+}$ and $\mathrm{Ge}^{4+} \mathrm{Co}-\mathrm{Doped} \mathrm{Bi}_{4} \mathrm{Si}_{3} \mathrm{O}_{12}$ Single Crystals for High Power Warm White LED
}

\author{
Tian Tian $\left.{ }^{(}\right)$, Haiwei Feng, Yan Zhang, Ding Zhou, Hui Shen, Hongchao Wang and Jiayue Xu * \\ Institute of Crystal Growth, School of Materials Science and Engineering, Shanghai Institute of Technology, \\ Shanghai 201418, China; tiant@sit.edu.cn (T.T.); 15214387282@163.com (H.F.); zhang.yan@vip.163.com (Y.Z.); \\ dzhou@sit.edu.cn (D.Z.); hshen@sit.edu.cn (H.S.); chaochao1993_3@sina.com (H.W.) \\ * Correspondence: xujiayue@sit.edu.cn; Tel./Fax: +86-021-608-735-81
}

Academic Editor: Ingo Hartenbach

Received: 14 July 2017; Accepted: 7 August 2017; Published: 9 August 2017

\begin{abstract}
Phi 1$ inch $\mathrm{Dy}^{3+}$ and $\mathrm{Ge}^{4+}$ co-doped bismuth silicate $\left(\mathrm{Bi}_{4} \mathrm{Si}_{3} \mathrm{O}_{12}, \mathrm{BSO}\right)$ single crystals with the length of $80-100 \mathrm{~mm}$ were successfully grown by Bridgman method. They are transparent, free of cracks and inclusions. The white residual at the top parts of BSO crystals disappears with co-doping $1 \mathrm{~mol} \% \mathrm{Dy}^{3+}$ and more than $3 \mathrm{~mol} \% \mathrm{Ge}^{4+}$. The FWHM values of X-ray rocking curves shows $1 \%$ Dy, $3 \%$ Ge:BSO crystal possesses high crystallization quality. The intrinsic emission peak of $\mathrm{BSO}$ and the characteristic emission peaks of $\mathrm{Dy}^{3+}$ ions are weakened with increasing the doping concentration of $\mathrm{Ge}^{4+} .1 \mathrm{~mol} \% \mathrm{Dy}^{3+}$ and $3 \mathrm{~mol} \% \mathrm{Ge}^{4+}$ are the optimal concentrations due to high crystallization quality and moderate emission intensity. The CIE coordinates and CCT values shift towards warmer white light region with increased $\mathrm{Ge}^{4+}$ co-doping. The CCT values are close to the ideal value of $3000 \mathrm{~K}$ for warm white light when $1 \% \mathrm{Dy}, 3 \% \mathrm{Ge}: \mathrm{BSO}$ crystal is excited by various UV light. Increasing the temperature from $298 \mathrm{~K}$ to $573 \mathrm{~K}$ leads the luminescence lifetime to decrease from $659 \mu$ s to $645 \mu \mathrm{s}$. More than $95 \%$ and $80 \%$ photoluminescence intensity at room temperature is still retained at $423 \mathrm{~K}$ and $573 \mathrm{~K}$ respectively. Dy,Ge:BSO crystals are potential candidates for fabricating high power warm WLEDs.
\end{abstract}

Keywords: $\mathrm{BSO}$ single crystal; $\mathrm{Dy}^{3+}$ and $\mathrm{Ge}^{4+}$ co-doping; Bridgman method; warm white LEDs; high power

\section{Introduction}

As a burgeoning technology, solid state lighting is rapidly developing and emerging as a greener candidate to replace the existing technology in the lighting industry. Especially, white light-emitting diodes (WLEDs) which made a major breakthrough in solid state lighting technology, are considered as a candidate for superseding conventional incandescent and fluorescent lamps owing to their advantages of long lifetime, low power consumption, high energy efficiency, good reliability, compactness, and environmental-friendly characteristics [1-5]. The correlated color temperature (CCT) rating for lamps is a general 'warmth' or 'coolness' measure of its appearance. Usually, WLEDs can be generally categorized as warm WLEDs $(<4000 \mathrm{~K})$ and cool WLEDs ( $\geq 4000 \mathrm{~K})[6,7]$. A rating of $3000 \mathrm{~K}$ is considered a more ideal CCT value for warm WLEDs with higher luminous efficacy of radiation and more energy efficiency [8]. Compared with the cool WLEDs, warm WLEDs have lower CCT and are closer to sunlight color, which is beneficial for keeping natural circadian rhythms in humans and offering more visibility.

Commercial WLEDs are assembled by combining a chip with powder phosphors, which are usually embedded in epoxy resins. This structure is unsuitable for fabricating high power WLEDs 
due to many drawbacks. The poor heat resistance of the epoxy resins cause the WLEDs to age more rapidly and the temperature increase of the chip results in lower luminous efficiency. Compared with powder phosphors, single crystals possess good anti-light irradiation, as well as good thermal, mechanical, and chemical stability. The rigid cyclic symmetric structure of single crystals results in high luminous efficiency of active ions. These are helpful for producing high power warm WLEDs to obtain high stability, long lifetime, high luminous efficiency, and excellent color $[9,10]$. Some reports have focused on yttrium aluminum garnet (YAG)-based fluorescent crystals for WLEDs, but its high melt point $\left(1950^{\circ} \mathrm{C}\right)$ results in a high cost and some difficulties in crystal growth [11,12]. Comparatively speaking, bismuth silicate $\left(\mathrm{Bi}_{4} \mathrm{Si}_{3} \mathrm{O}_{12}, \mathrm{BSO}\right)$ crystal which is an important scintillation material has a comparatively lower melt point $\left(1030^{\circ} \mathrm{C}\right)$, as well as other superior properties-large specific heat, small thermal expansion, high optical damage threshold, high optical transmittance, and high hardness-render it more suitable for serving as a fluorescent host for high power LEDs [10,13-15].

In recent years, as an important lanthanide ion, trivalent dysprosium ions $\left(\mathrm{Dy}^{3+}\right)$ were doped in various fluorescent hosts and have been widely studied for WLEDs. Because the visible luminescence of $\mathrm{Dy}^{3+}\left({ }^{4} \mathrm{f}_{9}\right)$ excited by UV light mainly consists of three bands in blue (470-500 nm), yellow (570-590 nm), and red $(655-670 \mathrm{~nm})$ regions, which results in white light emission. However, the CCT values of many fluorescent materials—such as some fluoride, tungstate, borate and silicate-are close to or even higher than $4000 \mathrm{~K}$ [16-26]. Our group has investigated the growth and properties of BSO crystals for several years $[10,14,15,27-31]$. According to our previous work, the yellow bands in $\mathrm{Dy}^{3+}$ doped BSO crystals are more intense than the blue bands [10], and when combined with the red bands they may deduce lower CCT relative to other $\mathrm{Dy}^{3+}$ doped materials. Meanwhile, crystallization quality is crucial for single crystal. However, due to the great difference of the melt point and density between $\mathrm{Bi}_{2} \mathrm{O}_{3}$ and $\mathrm{SiO}_{2}$, there is always precipitated phase at the top of $\mathrm{BSO}$ crystals. It was reported that doping germanium ions $\left(\mathrm{Ge}^{4+}\right)$ in BSO crystals could effectively modify the crystallization behavior and improve the quality [29]. However, the doping concentration of $\mathrm{Ge}^{4+}$ should be suitable because doping too much $\mathrm{Ge}^{4+}$ would cause the lattice to become seriously distorted and induce new electron traps, as well as lead to high cost [31].

To our knowledge, there are not many studies focused on crystal growth and luminescence properties of $\mathrm{Dy}^{3+}$ and $\mathrm{Ge}^{4+}$ co-doped BSO single crystals (Dy,Ge:BSO). In this paper, we report the growth of Dy,Ge:BSO single crystals by Bridgman method and demonstrate the capability of generating warm white light under excitation in the ultraviolet (UV) region.

\section{Materials and Methods}

It should be mentioned that the optimal concentration of $\mathrm{Dy}^{3+}$ is $1 \mathrm{~mol} \%$ as greater concentrations lead to doping concentration quenching [10]. High purity $\mathrm{Bi}_{2} \mathrm{O}_{3}(5 \mathrm{~N}), \mathrm{SiO}_{2}(4 \mathrm{~N}), \mathrm{GeO}_{2}(5 \mathrm{~N})$, and $\mathrm{Dy}_{2} \mathrm{O}_{3}(4 \mathrm{~N})$ were used as raw materials for Dy,Ge:BSO single crystals growth. These raw materials were weighed according to stoichiometric equation ratio of formula $\left(\mathrm{Bi}_{0.99} \mathrm{Dy}_{0.01}\right) 4\left(\mathrm{Si}_{1-\mathrm{x}} \mathrm{Ge}_{\mathrm{x}}\right)_{3} \mathrm{O}_{12}$ $(\mathrm{x}=0,0.01,0.03,0.05)$ and mixed in a ball mill coated with polyethylene for $12 \mathrm{~h}$. After that, the mixture was held at $750{ }^{\circ} \mathrm{C}$ for $8 \mathrm{~h}$ and then ground to powder and mixed again in the ball mill for $3 \mathrm{~h}$. The samples were put into the aluminum oxide crucible and held at $850^{\circ} \mathrm{C}$ for $12 \mathrm{~h}$ to prepare Dy, Ge:BSO polycrystalline powders. The feed materials were then put into the Pt crucibles to grow single crystals in a modified Bridgman furnace. The furnace temperature was kept at $1080^{\circ} \mathrm{C}$ to ensure the feed materials melted completely. The crystal growth rate was $0.2-0.5 \mathrm{~mm} / \mathrm{h}$ and the growth direction was along $z$-axis. The crystals doped with different concentration were labeled as $1 \% \mathrm{Dy}: \mathrm{BSO}$; $1 \% \mathrm{Dy}, 1 \% \mathrm{Ge}: \mathrm{BSO} ; 1 \% \mathrm{Dy}, 3 \% \mathrm{Ge}: \mathrm{BSO}$; and $1 \% \mathrm{Dy}, 5 \% \mathrm{Ge}: \mathrm{BSO}$, the number represents the molarity.

The X-ray powder diffraction of Dy,Ge:BSO crystal was collected with crushed clear crystals, using a D/max-2200 PC type diffractometer (Rigaku Co., Ltd., Tokyo, Japan) at room temperature. After the confirmation of the obtained phase, $2 \mathrm{~mm}$ thickness single crystal wafers were cut along the growth axis and polished to optical grade for measurement. High resolution X-ray rocking curve of the crystal plates were recorded by a Bruker HRXRD-5000 (Bruker Optics Inc., Billerica, MA, USA) 
to examine the crystalline quality of Dy,Ge:BSO crystal. The excitation and emission spectra of the samples were measured by a HITACHI F-7000 PL spectrophotometer (Hitachi High-Technologies Co., Tokyo, Japan) with a self-temperature controller, using a Xenon lamp as a light source. The CRI was measured by HAAS-2000 high accuracy array spectroradiometer (Everfine Photo-E-Info Co., Ltd., Hangzhou, China).

\section{Results and Discussions}

\subsection{Crystal Growth}

The XRD patterns of Dy,Ge:BSO samples are shown in Figure 1a. Based on the PDF\#35-1007, the XRD spectrum shows that the diffraction peaks and relative intensity of the crystal samples are very similar to those of BSO. That indicates that co-doping with $\mathrm{Dy}^{3+}$ and $\mathrm{Ge}^{4+}$ has a negligible effect on diffraction data. So the crystals have a cubic structure with the I-43d space group, and the current doping concentration does not induce any obvious peak shift or second phase. Since $\mathrm{Ge}^{4+}$ occupies the positions of $\mathrm{Si}^{4+}$ and the ionic radius of $\mathrm{Ge}^{4+}(39 \mathrm{pm})$ is larger than that of $\mathrm{Si}^{4+}(26 \mathrm{pm})$, the lattice constants of Dy,Ge:BSO samples become bigger with the enhancement of the $\mathrm{Ge}^{4+}$ doping level, as shown in Figure 1b.
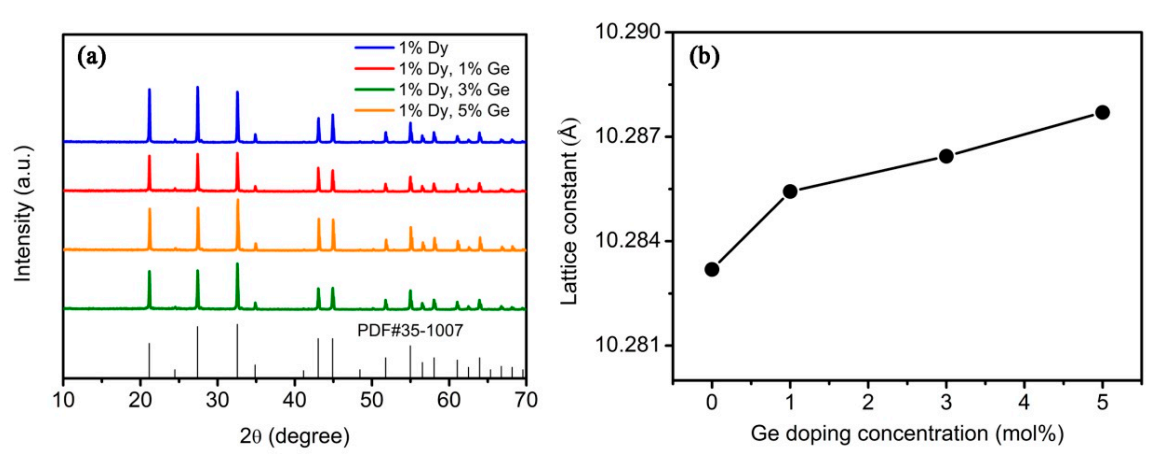

Figure 1. (a) Powder X-ray diffraction patterns of Dy,Ge:BSO crystals; (b) Lattice constants of Dy,Ge:BSO single crystals plotted against Ge content.

The as-grown Dy,Ge:BSO crystals and their top parts are shown in Figure 2, (a) $1 \mathrm{~mol} \% \mathrm{Dy}^{3+}$ doped, (b) $3 \mathrm{~mol} \% \mathrm{Ge}^{4+}$ doped, and (c) $3 \mathrm{~mol} \% \mathrm{Ge}^{4+}$ and $1 \mathrm{~mol} \% \mathrm{Dy}^{3+}$ co-doped. All of the crystals are 1 inch in diameter and $80-100 \mathrm{~mm}$ in length, while they are transparent and free of cracks and inclusions. However, the top parts of them differ substantially. As can be seen from Figure $2 a, b$, there is a white residual segregation layer at the top parts when mono-doping $\mathrm{Dy}^{3+}$ or $\mathrm{Ge}^{4+}$ ions into BSO crystals. When $1 \mathrm{~mol} \% \mathrm{Dy}^{3+}$ and $3 \mathrm{~mol} \% \mathrm{Ge}^{4+}$ are co-doped in BSO crystals, the top part is without any white residue, as shown in Figure 2c. The XRD patterns of the top parts for 1\%Dy:BSO and $1 \% \mathrm{Dy}, 3 \% \mathrm{Ge}: \mathrm{BSO}$ crystal are compared in Figure $2 \mathrm{~d}$. The top part of $1 \% \mathrm{Dy}, 3 \% \mathrm{Ge}$ :BSO crystal is pure BSO phase, while the segregated phase of the white residue for $1 \% \mathrm{Dy}: \mathrm{BSO}$ is polycrystalline $\mathrm{SiO}_{2}$ (tridymite). It should be mentioned that $1 \% \mathrm{Dy}, 5 \% \mathrm{Ge}: \mathrm{BSO}$ crystal is also free of the white residue. Obviously, the white residual disappears until more than $3 \mathrm{~mol} \% \mathrm{Ge}^{4+}$ is co-doped. As the X-ray rocking curves of $1 \% \mathrm{Dy}: \mathrm{BSO}$ and $3 \% \mathrm{Ge}: \mathrm{BSO}$ crystal are nearly the same, we just present the results of $1 \% \mathrm{Dy}: \mathrm{BSO}$ and $1 \% \mathrm{Dy}, 3 \% \mathrm{Ge}: \mathrm{BSO}$ crystals for comparison, as shown in Figure 2e. The full width at half maximum (FWHM) of these two samples are measured to be about 57" and 24" respectively, which implies that $1 \% \mathrm{Dy}, 3 \% \mathrm{Ge}: \mathrm{BSO}$ crystal possesses higher crystallization quality. Thus, co-doping $\mathrm{Dy}^{3+}$ and $\mathrm{Ge}^{4+}$ ions with proper concentrations can substantially modify the crystallization behavior and improve the quality of BSO crystal. 


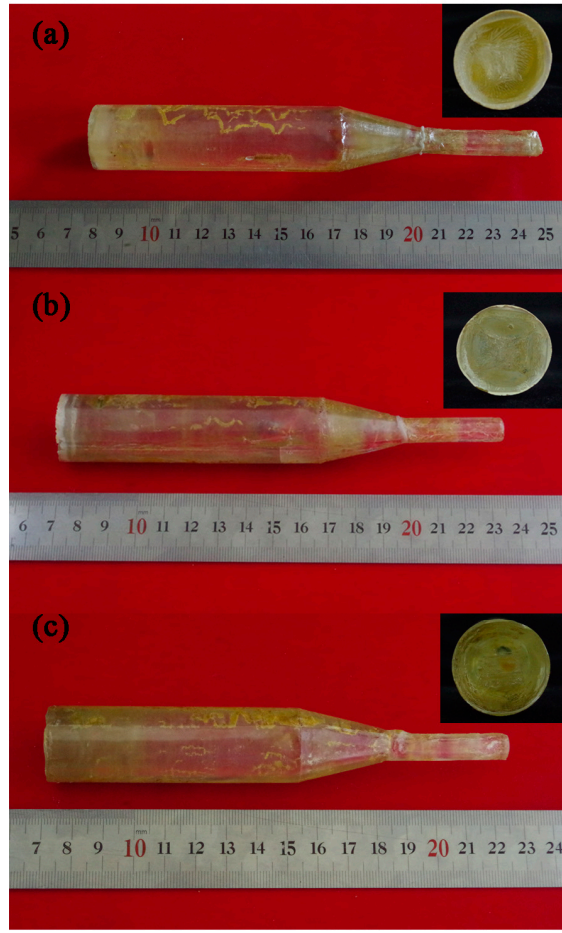

(d)

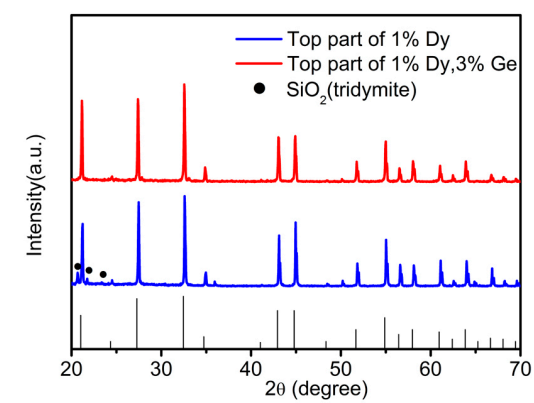

(e)

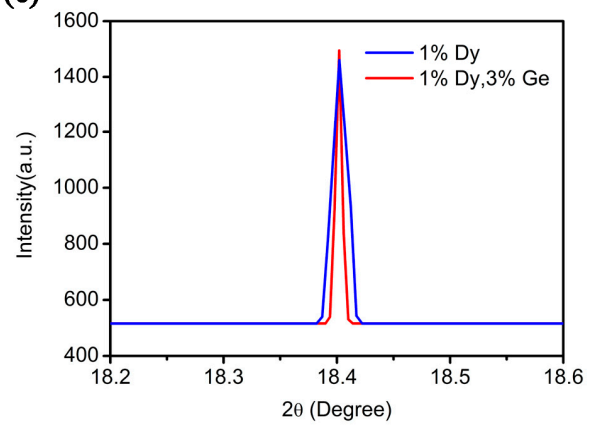

Figure 2. (a-c) As grown Dy,Ge:BSO single crystals and their top parts; (d) XRD pattern of the white residual, and (e) X-ray rocking curves of (001) reflection for 1\%Dy:BSO and 1\%Dy,3\%Ge:BSO crystals.

\subsection{Fluorescence Spectra}

Taking valence states, crystallochemical behavior, and ionic radii of $\mathrm{Bi}^{3+}(103 \mathrm{pm}), \mathrm{Si}^{4+}(26 \mathrm{pm})$, and $\mathrm{Dy}^{3+}(91 \mathrm{pm})$ into consideration, $\mathrm{Dy}^{3+}$ ions replaced $\mathrm{Bi}^{3+}$ ions site easily in $\mathrm{BSO}$ crystal. So the site occupied by $\mathrm{Dy}^{3+}$ was the same as that of $\mathrm{Bi}^{3+}$ with $C_{1}$ site symmetry based on crystallographic structure of BSO. Figure 3a shows the photoluminescence excitation spectrum of Dy,Ge:BSO crystals recorded by monitoring the emission at $574 \mathrm{~nm}$ corresponding to the ${ }^{4} \mathrm{~F}_{9 / 2} \rightarrow{ }^{6} \mathrm{H}_{13 / 2}$ transition. It can clearly be seen that a broad band in the range from $220 \mathrm{~nm}$ to $310 \mathrm{~nm}$ corresponds to the oxygen to bismuth charge transfer band. Besides, the spectrum also displays five other bands centered at 324, 349,363 , and $391 \mathrm{~nm}$ in the UV region, which are attributed to the $4 \mathrm{f}-4 \mathrm{f}$ transitions of $\mathrm{Dy}^{3+}$ and from ${ }^{6} \mathrm{H}_{15 / 2}$ ground state to ${ }^{6} \mathrm{P}_{3 / 2},{ }^{6} \mathrm{P}_{7 / 2},{ }^{6} \mathrm{P}_{5 / 3}$, and ${ }^{4} \mathrm{I}_{13 / 2}$ excited states, respectively. The fluorescence emission spectra of Dy,Ge:BSO single crystals and powered Dy,Ge:BSO single crystals excited by $290 \mathrm{~nm}$ are shown in Figure 3b,c. The spectra mainly consist of three emission peaks located at 486, 574 , and $662 \mathrm{~nm}$, which correspond to the transitions of ${ }^{4} \mathrm{~F}_{9 / 2}-{ }^{6} \mathrm{H}_{15 / 2},{ }^{4} \mathrm{~F}_{9 / 2}-{ }^{6} \mathrm{H}_{13 / 2}$, and ${ }^{4} \mathrm{~F}_{9 / 2}{ }^{-}{ }^{6} \mathrm{H}_{11 / 2}$, respectively. Besides, pure $\mathrm{BSO}$ only has a broad emission band located at about $480 \mathrm{~nm}$. The intrinsic emission peaks of BSO peaked at $480 \mathrm{~nm}$ and the characteristic emission peaks of $\mathrm{Dy}^{3+}$ ions peaked at 486,574 , and $662 \mathrm{~nm}$ are weakened with the improvement of $\mathrm{Ge}^{4+}$ doping level.

Even though the emission intensity of $1 \%$ Dy, $3 \%$ Ge:BSO crystal is weaker than $1 \%$ Dy:BSO crystal, it is still the optimal choice due to the high crystallization quality and moderate emission intensity. The emission spectra of $1 \%$ Dy,3\%Ge:BSO crystal excited by 290, 324, 349, 363, and $391 \mathrm{~nm}$ is also measured and presented in Figure 4a. Obviously, though the excitation intensity of $290 \mathrm{~nm}$ is not the strongest, the emission intensity of the crystal excited under $290 \mathrm{~nm}$ is much stronger than excited under other lights. It is indicated that the energy absorbed by Bi atoms is transferred to $\mathrm{Dy}^{3+}$. The emission mechanism of Dy,Ge:BSO crystals is depicted in the partial energy level diagram, as shown in Figure $4 b$. 

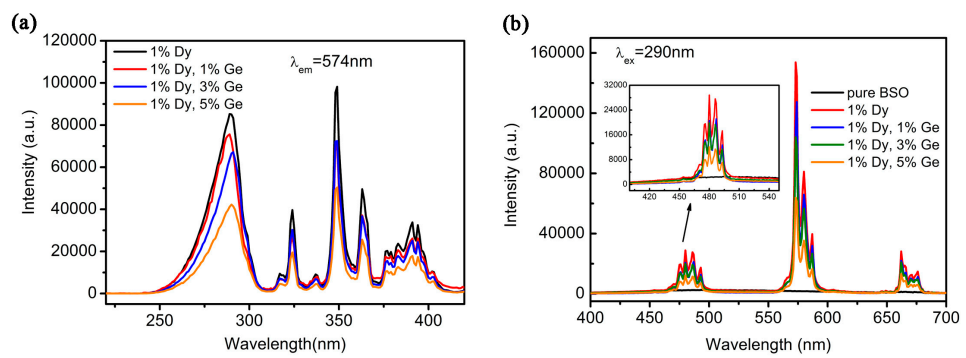

(c)

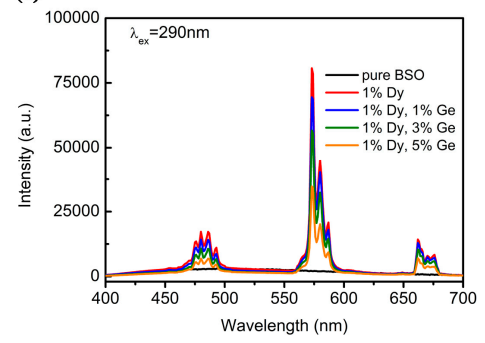

Figure 3. (a) Excitation spectra of Dy,Ge:BSO crystals by monitoring the emission at $574 \mathrm{~nm}$; (b) and (c) Emission spectra of Dy,Ge:BSO single crystals and powered Dy,Ge:BSO single crystals excited by $290 \mathrm{~nm}$.

(a)

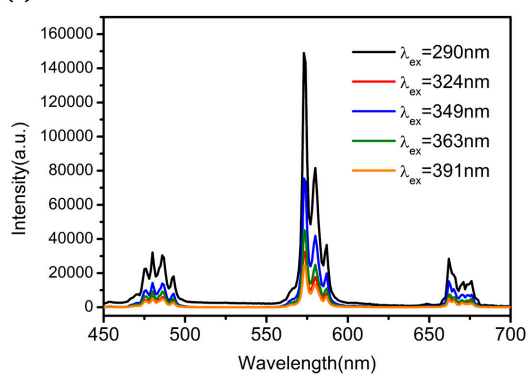

(b)

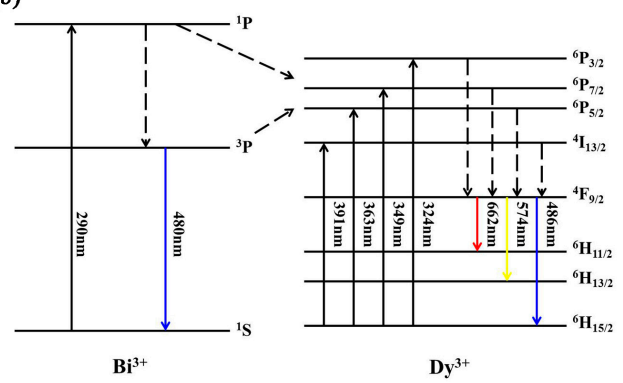

Figure 4. (a) Emission spectrum of $1 \% \mathrm{Dy}, 3 \% \mathrm{Ge}$ :BSO crystal and (b) the partial energy level diagram.

\subsection{CIE Coordinates and CCT Values}

In order to further investigate the emission color of Dy,Ge:BSO crystals, the Commission International de L'Eclairage (CIE) chromaticity coordinates under different UV excitations were calculated using the corresponding emission spectrum in Figures $3 \mathrm{~b}$ and $4 \mathrm{a}$, and are listed in Table 1. As shown in Figure 5a, under the excitation light of $290 \mathrm{~nm}$, the coordinates of Dy,Ge:BSO crystals shift along the direction of warmer white light region when the concentration of $\mathrm{Ge}^{4+}$ is increased. That means co-doped $\mathrm{Ge}^{4+}$ in Dy:BSO crystals is helpful to emitting warmer white light. From Figure $5 b$, we can also see when $1 \%$ Dy, $3 \%$ Ge:BSO crystal is excited by $290,324,349,363$, and $391 \mathrm{~nm}$, the coordinate is $(0.456,0.457),(0.446,0.432),(0.447,0.435),(0.443,0.428)$, and $(0.443,0.429)$, respectively. If the wavelength of excited light is longer than $290 \mathrm{~nm}$, all of the coordinates turn to almost the same $(0.45,0.43)$ and are in the region of warm white light. Although the coordinates deviate slightly from others under the excitation wavelength of $290 \mathrm{~nm}$, it is still in the region of warm white light. The inset is the polished 1\%Dy,3\%Ge:BSO crystal, emitting brightly warm white light under $365 \mathrm{~nm}$ UV light illumination, which is the common wavelength of commercial UV LED chip and just close to the excitation peak centered at $363 \mathrm{~nm}$ in our samples. It should be mentioned that the intensity of this excitation peak is lower than that of the peaks located at $290 \mathrm{~nm}$ and $349 \mathrm{~nm}$. This means our samples can be more efficiently excited if a $290 \mathrm{~nm}$ or $349 \mathrm{~nm}$ UV-LED chip could be developed. So the results mean that no significant change is observed and stable warm white light can be emitted with variation of the excitation wavelength from $290 \mathrm{~nm}$ to $390 \mathrm{~nm}$. 

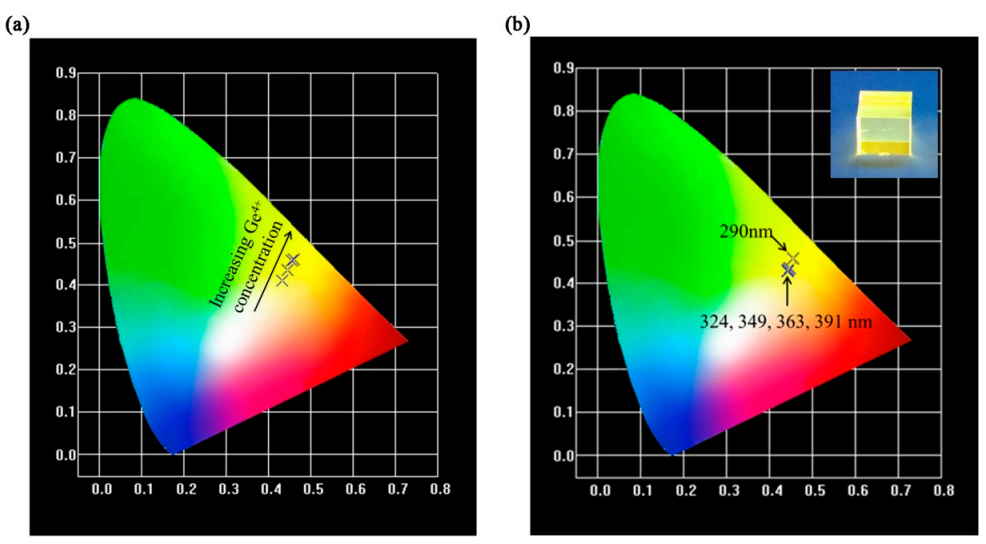

Figure 5. (a) CIE chromaticity diagram of Dy,Ge:BSO crystals with different $\mathrm{Ge}^{4+}$ concentrations excited by $290 \mathrm{~nm}$; (b) CIE chromaticity diagram of 1\%Dy,3\%Ge:BSO crystal excited by different UV light (inset is the polished sample under UV light).

In lighting industry, the quality of light emitted by any light sources is also examined in terms of CCT [32], which demonstrates the temperature of the closest Planckian black-body radiation to the operating point on the CIE chromaticity diagram [33]. Here the CCT values of Dy,Ge:BSO crystal were evaluated using the equation as follows which proposed by McCamy [32]

$$
\mathrm{CCT}=-449 n^{3}+3525 n^{2}-6824 n+5520.33
$$

where $\mathrm{n}=\left(\mathrm{x}-\mathrm{x}_{\mathrm{e}}\right) /\left(\mathrm{y}-\mathrm{y}_{\mathrm{e}}\right)$ is the inverse slope line and $\left(\mathrm{x}_{\mathrm{e}}=0.332, \mathrm{y}_{\mathrm{e}}=0.186\right)$ is the epicenter.

Table 1. Comparison of coordinates and CCT values of Dy,Ge:BSO crystals, different Dy-doped fluorescent materials and standards.

\begin{tabular}{|c|c|c|c|c|c|}
\hline \multirow{2}{*}{ Samples } & \multirow{2}{*}{$\begin{array}{c}\text { Excitation } \\
\text { Wavelength (nm) }\end{array}$} & \multicolumn{2}{|c|}{ Coordinate } & \multirow{2}{*}{ ССТ (K) } & \multirow{2}{*}{ Ref. } \\
\hline & & $\mathbf{x}$ & $\mathbf{y}$ & & \\
\hline $1 \%$ Dy & 290 & 0.432 & 0.411 & 3139 & \multirow{8}{*}{ This work } \\
\hline 1\%Dy,1\%Ge:BSO & 290 & 0.445 & 0.435 & 3103 & \\
\hline $1 \% \mathrm{Dy}, 3 \% \mathrm{Ge}: \mathrm{BSO}$ & 290 & 0.456 & 0.457 & 3088 & \\
\hline $1 \% \mathrm{Dy}, 5 \% \mathrm{Ge}: \mathrm{BSO}$ & 290 & 0.460 & 0.461 & 3058 & \\
\hline \multirow{4}{*}{ 1\%Dy,3\%Ge:BSO } & 324 & 0.446 & 0.432 & 3066 & \\
\hline & 349 & 0.447 & 0.435 & 3072 & \\
\hline & 363 & 0.443 & 0.428 & 3084 & \\
\hline & 391 & 0.443 & 0.429 & 3091 & \\
\hline Standard white & & 0.33 & 0.33 & 5455 & {$[34]$} \\
\hline Fluorescent tube & - & - & - & 3937 & [35] \\
\hline Tungsten lamp & - & - & - & 2836 & [35] \\
\hline Ideal warm white light & - & - & - & 3000 & [8] \\
\hline YAG & Blue chip & 0.29 & 0.30 & 5610 & [36] \\
\hline $3 \% \mathrm{Dy}: \mathrm{SrF}_{2}$ & 349 & 0.333 & 0.337 & 5475 & [20] \\
\hline $2 \% \mathrm{Dy}: \beta-\mathrm{NaYF}_{4}$ & 351 & 0.323 & 0.371 & 5860 & [21] \\
\hline $2 \% \mathrm{Dy}: \mathrm{Gd}_{3} \mathrm{Ga}_{5} \mathrm{O}_{12}$ & 277 & 0.32 & 0.34 & 6073 & [22] \\
\hline $1 \% \mathrm{Dy}: \mathrm{CaWO}_{4}$ & 353 & 0.363 & 0.407 & 4631 & {$[23]$} \\
\hline $1 \% \mathrm{Dy}: \mathrm{Li}_{4} \mathrm{CaB}_{2} \mathrm{O}_{6}$ & UV GaN & 0.39 & 0.41 & 3983 & [24] \\
\hline $1 \% \mathrm{Dy}: \mathrm{Sr}_{2} \mathrm{SiO}_{4}$ & 350 & 0.351 & 0.389 & 4884 & [25] \\
\hline $5 \% \mathrm{Dy}: \mathrm{CdSiO}_{3}$ & 254 & 0.387 & 0.376 & 4000 & [26] \\
\hline
\end{tabular}

Table 1 shows the CCT values of Dy,Ge:BSO crystals excited by $290 \mathrm{~nm}$ and the optimized $1 \%$ Dy, $3 \%$ Ge:BSO crystal excited by different UV light. Besides, some standards and some other 
Dy-doped fluorescent materials are presented for comparison. It is clearly seen that the CCT values of Dy,Ge:BSO crystals decrease with the enhancement of $\mathrm{Ge}^{4+}$ concentration, and fall in the warm white light region $(\mathrm{CCT} \leq 4000 \mathrm{~K}$ ). When the optimized $1 \% \mathrm{Dy}, 3 \% \mathrm{Ge}: \mathrm{BSO}$ crystal is excited by different UV light, the CCT values are in the range of 3066-3091 K. Compared with some standards, the CCT values of $1 \% \mathrm{Dy}, 3 \% \mathrm{Ge}: \mathrm{BSO}$ are lower than those of standard white (5455 K) [34], fluorescent tube (3937K) [35], YAG+blue chips [36]; higher than that of tungsten lamp (2836 K) [35]; and especially very close to the ideal CCT value of warm white light $(3000 \mathrm{~K})$ [8]. Besides, the CCT values are much lower than many other $\mathrm{Dy}^{3+}$ doped compounds, such as some fluoride, tungstate, borate, and silicate [20-26]. Simple LEDs were fabricated by combining the commercial $365 \mathrm{~nm}$ UV-LED chips with Dy,Ge:BSO crystals. The color-rendering index of $1 \%$ Dy:BSO; $1 \%$ Dy, $1 \% G e: B S O ; 1 \% D y, 3 \% G e: B S O$; and $1 \% \mathrm{Dy}, 5 \% \mathrm{Ge}: \mathrm{BSO}$ was calculated under a forward-bias current of $30 \mathrm{~mA}$, and they are $64.3,69.0$, 72.8 , and 76.0 , respectively.

\subsection{Thermal Stability}

Thermal stability of fluorescence materials for WLEDs is one of the most important technological parameters, high-power WLEDs should operate above $423 \mathrm{~K}$ [37]. Thus, it is important to evaluate the thermal stability of fluorescent materials for practical application. The temperature dependence of the decay curves of $1 \% \mathrm{Dy}, 3 \% \mathrm{Ge}: \mathrm{BSO}$ crystal have been measured. The curves corresponding to ${ }^{4} \mathrm{~F}_{9 / 2}-{ }^{6} \mathrm{H}_{13 / 2}$ transition around $574 \mathrm{~nm}$ upon $290 \mathrm{~nm}$ excitation are presented in Figure 6a. Each decay curve can be described to good approximation to a single exponential function in the temperature range of $298-573 \mathrm{~K}$, which indicates that $\mathrm{Dy}^{3+}$ occupies only one site. The lifetime value can be fitted as

$$
\mathrm{I}=\mathrm{I}_{0} \exp (-\mathrm{t} / \tau)
$$

where $I_{0}$ is the initial emission intensity for $t=0$ and $\tau$ is the lifetime. The lifetime values are plotted in Figure $6 \mathrm{~b}$ as a function of recording temperature. As can been seen from Figure $7 \mathrm{~b}$, the lifetime is slightly shortened from $659 \mu$ s to $654 \mu$ s as increasing temperature from $298 \mathrm{~K}$ to $523 \mathrm{~K}$, and then it quickly drops to $645 \mu$ s when the temperature rises to $573 \mathrm{~K}$. This result shows the crystal has high thermal stability. The drop of the $\mathrm{Dy}^{3+}$ emission lifetime indicates the presence of a typical temperature quenching behavior between $\mathrm{Dy}^{3+}$ ions. In the thermal quenching process, energy transfer may occur from $\mathrm{Dy}^{3+}$ to killer centers or to any other defect centers near the $\mathrm{Dy}^{3+}$ ions by thermal phonon assistance.

(a)

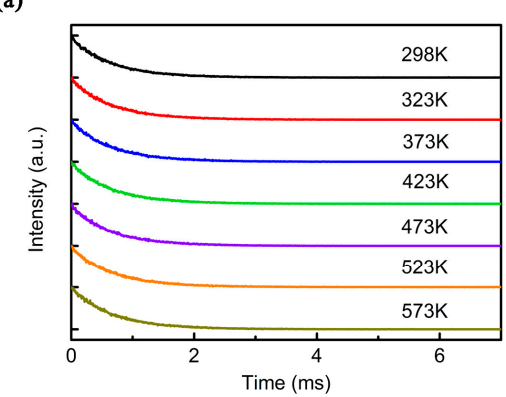

(b)

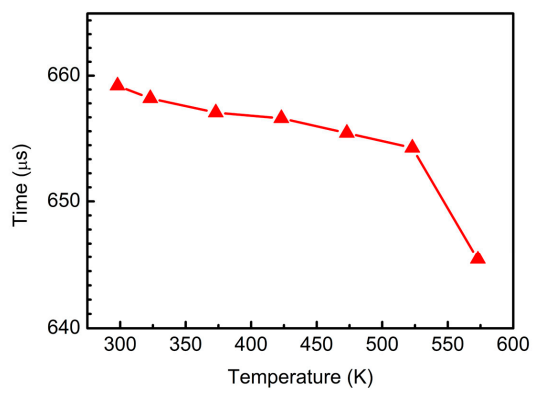

Figure 6. (a) Luminescence decay curves of $1 \% \mathrm{Dy}, 3 \% \mathrm{Ge}: \mathrm{BSO}$ crystal measured at different temperature by excitation at $290 \mathrm{~nm}$ and monitoring the ${ }^{4} \mathrm{~F}_{9 / 2}-{ }^{6} \mathrm{H}_{13 / 2}$ emission; (b) Luminescence decay lifetime as a function of temperature for $1 \% \mathrm{Dy}, 3 \% \mathrm{Ge}: \mathrm{BSO}$ crystal. 
(a)

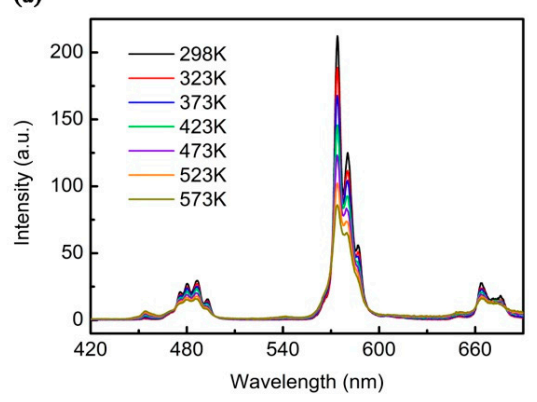

(b)

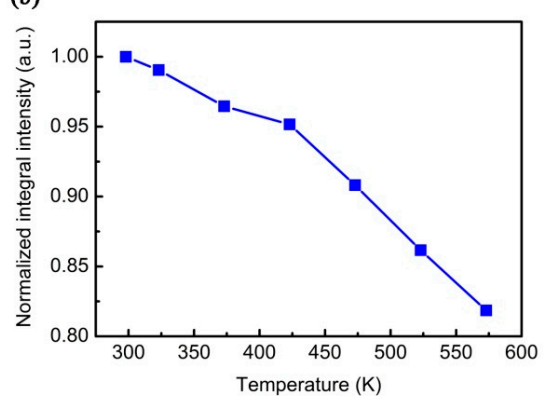

Figure 7. (a) Temperature-dependent emission spectra and (b) integral intensity of $1 \% \mathrm{Dy}, 3 \% \mathrm{Ge}$ :BSO crystal excited by $290 \mathrm{~nm}$ at different temperature.

The temperature dependent emission spectra of $1 \% \mathrm{Dy}, 3 \% \mathrm{Ge}: \mathrm{BSO}$ crystal, measured at various temperatures ranging from $298 \mathrm{~K}$ to $573 \mathrm{~K}$ and recorded at the excitation of $290 \mathrm{~nm}$, is presented in Figure 7a. It is clearly observed that the shapes of the emission peaks are similar and no emission bands shift at different temperatures. However, the intensity of the emission peaks decrease with the incensement of temperature, which can be described by thermal quenching. The thermal quenching temperature $\left(\mathrm{T}_{1 / 2}\right)$ is defined as the temperature at which the emission intensity is $50 \%$ of its original intensity. Thus, the value of the thermal quenching temperature can be deduced from the intensity of emission peaks at different temperature. The thermal quenching temperature $T_{1 / 2}$ is found to be as high as $523 \mathrm{~K}$. Furthermore, the normalized integrated photoluminescence intensity as a function of temperature is illustrated in Figure $7 \mathrm{~b}$, the photoluminescence intensity increases gradually as the temperature declines. The photoluminescence intensity of the crystal only decreases $4.8 \%$ of the initial value when the temperature increases from room temperature to $423 \mathrm{~K}$, exhibiting much smaller thermal quenching than YAG: $\mathrm{Ce}^{3+}(\sim 80 \%)$ [38], $\mathrm{Y}_{2} \mathrm{O}_{3}: \mathrm{Eu}^{3+}(\sim 74 \%)$ [39]. Moreover, more than 80\% PL intensity at room temperature is still retained even at the high temperature of $573 \mathrm{~K}$. Besides, as shown in Figure $8 \mathrm{a}$, the coordinates of $1 \% \mathrm{Dy}, 3 \% \mathrm{Ge}$ :BSO crystal are near the coordinates of $(0.46,0.46)$ with the improvement of temperature. The CCT value of it is improved just from $3088 \mathrm{~K}$ to $3190 \mathrm{~K}$ when the temperature increases from $298 \mathrm{~K}$ to $573 \mathrm{~K}$, as shown in Figure 8b. The above results definitely indicate that $1 \% \mathrm{Dy}, 3 \% \mathrm{Ge}: \mathrm{BSO}$ crystal has excellent thermal stability.

(a)

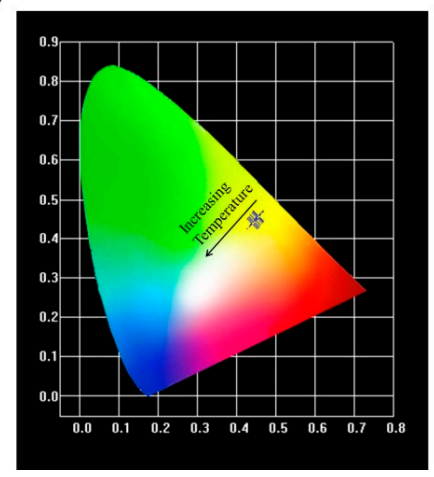

(b)

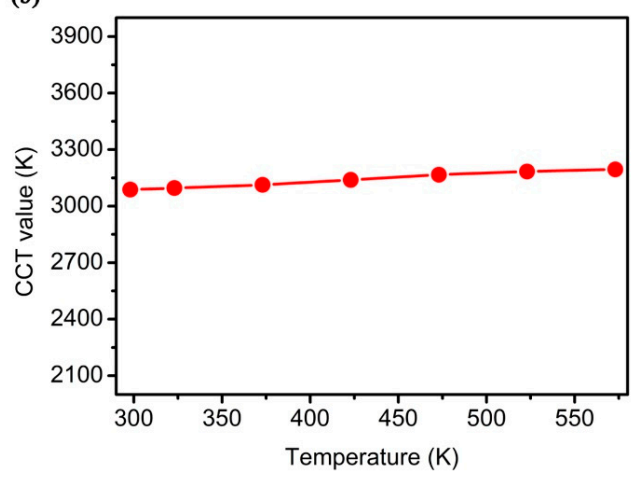

Figure 8. (a) CIE chromaticity diagram and (b) CCT values of $1 \% \mathrm{Dy}, 3 \% \mathrm{Ge}: \mathrm{BSO}$ crystal excited by $290 \mathrm{~nm}$ at different temperature.

\section{Conclusions}

$\mathrm{Dy}^{3+}$ and $\mathrm{Ge}^{4+}$ co-doped BSO single crystals were successfully grown by Bridgman method. The crystals are 1 inch in diameter and about $80-100 \mathrm{~mm}$ in length. All of them are transparent, free of cracks and inclusions. When $1 \mathrm{~mol} \%$ Dy and more than $3 \mathrm{~mol} \% \mathrm{Ge}$ are co-doped, the 
crystallization behavior of BSO crystals can be greatly modified and the top parts are free of white residual. The FWHM values of X-ray rocking curves show 1\%Dy,3\%Ge:BSO crystal possesses high crystallization quality. The intrinsic emission peak of BSO located at $480 \mathrm{~nm}$ and the characteristic emission peaks of $\mathrm{Dy}^{3+}$ ions located at 486,574 , and $662 \mathrm{~nm}$ are weakened with increasing the concentration of $\mathrm{Ge}^{4+} .1 \mathrm{~mol} \% \mathrm{Dy}^{3+}$ and $3 \mathrm{~mol} \% \mathrm{Ge}^{4+}$ are the optimal concentrations of Dy,Ge:BSO crystals for high crystallization quality and moderate emission intensity. The CIE coordinates and CCT values shift towards the warmer white light region with the improvement of $\mathrm{Ge}^{4+}$ doping concentration. The CCT values are close to the ideal warm white light value of $3000 \mathrm{~K}$ when $1 \%$ Dy, $3 \% \mathrm{Ge}: \mathrm{BSO}$ crystal is excited by various UV light, which exhibits stable warm white light emission. The luminescence lifetime of the crystal decreases from $659 \mu$ s to $645 \mu$ s with increasing temperature from $298 \mathrm{~K}$ to $573 \mathrm{~K}$. The shapes and location of the emission bands for $1 \% \mathrm{Dy}, 3 \% \mathrm{Ge}: \mathrm{BSO}$ crystal are unchanged with the increment of temperature. The photoluminescence intensity only decreases $4.8 \%$ of the initial value when the temperature increases to $423 \mathrm{~K}$, and even more than $80 \%$ photoluminescence intensity at room temperature is still retained at the high temperature of $573 \mathrm{~K}$. The CCT value is improved from $3088 \mathrm{~K}$ to $3190 \mathrm{~K}$ by increasing the temperature from $298 \mathrm{~K}$ to $573 \mathrm{~K}$. These results show that Dy,Ge:BSO can be a promising candidate for fabricating high power warm WLEDs.

Acknowledgments: This work was partially supported by the National Natural Science Foundation of China (51472263, 51572175, and 61605116), Shanghai Innovation action plan project (15520503400), Jiangsu Planned Projects for Postdoctoral Research Funds (1501131C), Shanghai Planned Projects for Young Teacher Training of Universities (ZZyy15087).

Author Contributions: Tian Tian and Jiayue $\mathrm{Xu}$ conceived and designed the experiments. Tian Tian and Haiwei Feng performed the experiments, and analyzed the data. Yan Zhang, Ding Zhou, Hui Shen, and Hongchao Wang contributed the measurements. Tian Tian wrote the manuscript. All authors read and approved the final version of the manuscript to be submitted.

Conflicts of Interest: The authors declare no conflict of interest.

\section{References}

1. Schubert, E.F.; Kim, J.K. Solid-state light sources getting smart. Science 2005, 308, 1274-1278. [CrossRef] [PubMed]

2. Shur, M.S.; Zukauskas, R. Solid-state lighting: Toward superior illumination. Proc. IEEE 2005, 93, 1691-1703. [CrossRef]

3. Krames, M.R.; Shchekin, O.B.; Mach, R.M.; Mueller, G.O.; Zhou, L.; Harbers, G.; Craford, M.G. Status and future of high-power light-emitting diodes for solid-state lighting. J. Disp. Technol. 2007, 3, 160-175. [CrossRef]

4. Park, S.H.; Lee, K.H.; Unithrattil, S.; Yoon, H.S.; Jang, H.G.; Im, W.B. Melilite-structure $\mathrm{CaYAl}_{3} \mathrm{O}_{7}$ :Eu ${ }^{3+}$ phosphor: Structural and optical characteristics for near-UVLED-based white light. J. Phys. Chem. C 2012, 116, 26850-26856. [CrossRef]

5. Jang, J.W.; Kim, J.S.; Kwon, O.H.; Lee, T.H.; Cho, Y.S. UV-curable silicate phosphor planar films printed on glass substrate for white light-emitting diodes. Opt. Lett. 2015, 40, 3723-3726. [CrossRef] [PubMed]

6. Shrivastava, R.; Kaur, J.; Dubey, V. White light emission by Dy ${ }^{3+}$ doped phosphor matrices: A short review. J. Fluoresc. 2016, 26, 105-111. [CrossRef] [PubMed]

7. Lakshminarayana, G.; Baki, S.O.; Lira, A.; Kityk, I.V.; Caldiño, U.; Kawa, U.; Kaky, M.; Mahdi, M.A. Structural, thermal and optical investigations of $\mathrm{Dy}^{3+}$-doped $\mathrm{B}_{2} \mathrm{O}_{3}-\mathrm{WO}_{3}-\mathrm{ZnO}-\mathrm{Li}_{2} \mathrm{O}-\mathrm{Na}_{2} \mathrm{O}$ glasses for warm white light emitting applications. J. Lumin. 2017, 186, 283-300. [CrossRef]

8. Phillips, J.M.; Coltrin, M.E.; Crawford, M.H.; Fischer, A.J.; Krames, M.R.; Mach, R.M.; Mueller, G.O.; Ohno, Y.; Rohwer, L.E.S.; Simmons, J.A.; et al. Research challenges toultra-efficient inorganic solid-state lighting. Laser Photonics Rev. 2007, 1, 307-333. [CrossRef]

9. Cui, Z.G.; Jia, G.H.; Deng, D.G.; Hua, Y.J.; Zhao, S.L.; Huang, L.H.; Wang, H.P.; Ma, H.P.; Xu, S.Q. Synthesis and luminescence properties of glass ceramics containing $\mathrm{MSiO}_{3}: \mathrm{Eu}^{2+}(\mathrm{M}=\mathrm{Ca}, \mathrm{Sr}, \mathrm{Ba})$ phosphors for white LED. J. Lumin. 2012, 132, 153-160. [CrossRef] 
10. Yang, B.B.; Xu, J.Y.; Zhang, Y.; Chu, Y.Q.; Wang, M.L.; Wen, Y.X. A yellow emitting phosphor Dy:Bi $\mathrm{B}_{4} \mathrm{Si}_{3} \mathrm{O}_{12}$ crystal for LED application. Mater. Lett. 2014, 135, 176-179. [CrossRef]

11. Anastasya, L.; Makoto, W.; Daisuke, I.; Kazuo, A.; Yoshiyuki, S.; Encarnacion, G.V.; Kiyoshi, S. Properties of Czochralski grown Ce, Gd: $\mathrm{Y}_{3} \mathrm{Al}_{5} \mathrm{O}_{12}$ single crystal for white light-emitting diode. J. Alloy. Compd. 2013, 553, 89-92.

12. Xiang, W.D.; Zhong, J.S.; Zhao, Y.S.; Liang, X.J.; Dong, Y.J.; Zhang, Z.M.; Chen, Z.P.; Liu, B.F. Growth and characterization of air annealing Mn-doped YAG:Ce single crystal for LED. J. Alloy. Compd. 2012, 542, 218-221. [CrossRef]

13. Shimizu, H.; Miyahara, F.; Hariu, H.; Hayakawa, T.; Ishikawa, T.; Itaya, M.; Iwata, T.; Kinoshita, T.; Moriya, M.; Nakabayashi, T.; et al. First beam test on a BSO electromagnetic calorimeter. Nucl. Instrum. Methods Phys. Res. A 2005, 550, 258-266. [CrossRef]

14. Zhang, Y.; Xu, J.Y.; Lu, B.L. Spectroscopic properties of $\mathrm{Dy}^{3+}: \mathrm{Bi}_{4} \mathrm{Si}_{3} \mathrm{O}_{12}$ single crystal. J. Alloy. Compd. 2014, 582, 635-639. [CrossRef]

15. Shen, H.; Xu, J.Y.; Ping, W.J.; He, Q.B.; Zhang, Y.; Jin, M.; Jiang, G.J. Mechanical and thermal properties of $\mathrm{Bi}_{4} \mathrm{Si}_{3} \mathrm{O}_{12}$ single crystals. Chin. Phys. Lett. 2012, 29, 076501. [CrossRef]

16. Yang, F.; Ma, H.X.; Liu, Y.F.; Han, B.; Feng, H.; Yu, Q.M. Photoluminescence properties of novel Dy ${ }^{3+}$ doped $^{-}$ $\mathrm{Ba}_{5} \mathrm{CaAl}_{4} \mathrm{O}_{12}$ phosphors. Ceram. Int. 2014, 40, 10189-10192. [CrossRef]

17. Liang, C.H.; Teoh, L.G.; Liu, K.T.; Chang, Y.S. Near white light emission of $\mathrm{BaY}_{2} \mathrm{ZnO}_{5}$ doped with Dy ${ }^{3+}$ ions. J. Alloy. Compd. 2012, 517, 9-13. [CrossRef]

18. Wang, J.Y.; Wang, J.B.; Duan, P. Luminescent properties of $\mathrm{Dy}^{3+}$ doped $\mathrm{Sr}_{3} \mathrm{Y}_{(}\left(\mathrm{PO}_{4}\right)_{3}$ for white LEDs. Mater. Lett. 2013, 107, 96-98. [CrossRef]

19. Liu, Q.B.; Liu, Y.F.; Ding, Y.J.; Peng, Z.M.; Tian, X.D.; Yu, Q.M.; Dong, G.Y. A White light emitting luminescent material Ba $\mathrm{Y}_{3}\left(\mathrm{PO}_{4}\right)_{3}: \mathrm{Dy}^{3+}$. Ceram. Int. 2014, 40, 10125-10129. [CrossRef]

20. Nini, K.; Singh, N.P.; Singh, L.P.; Krishna, S.S. Enhancement of luminescence in white emitting strontium fluoride core @ calcium fluoride shell nanoparticles. Nanoscale Res. Lett. 2015, 10, 347.

21. Cao, C.; Yang, H.K.; Chung, J.W.; Moon, B.K.; Choi, B.C.; Jeong, J.H.; Kim, K.H. Hydrothermal synthesis and white luminescence of $\mathrm{Dy}^{3+}$-doped $\mathrm{NaYF}_{4}$ microcrystals. J. Am. Ceram. Soc. 2011, 94, 3405-3411. [CrossRef]

22. Lü, W.; Zhou, H.; Chen, G.; Li, J.; Zhu, Z.; You, Z.; Tu, C. Photoluminescence Properties of Neat and $\mathrm{Dy}^{3+}$-Doped $\mathrm{Gd}_{3} \mathrm{Ga}_{5} \mathrm{O}_{12}$ Nanocrystals. J. Phys. Chem. C 2009, 113, 3844-3849. [CrossRef]

23. Du, P.; Bharat, L.K.; Guan, X.Y.; Yu, J.S. Synthesis and luminescence properties of color-tunable Dy ${ }^{3+}$-activated $\mathrm{CaWO}_{4}$ phosphors. J. Appl. Phys. 2015, 117, 083112. [CrossRef]

24. Neharika, J.; Kumar, V.; Singh, V.K.; Sharma, J.; Ntwaeaborwa, O.M.; Swart, H.C. Synthesis and photoluminescence study of a single dopant near white light emitting $\mathrm{Li}_{4} \mathrm{CaB}_{2} \mathrm{O}_{6}: \mathrm{Dy}^{3+}$ nanophosphor. J. Alloy. Compd. 2016, 688, 939-945. [CrossRef]

25. Zhang, L.; Lu, Z.; Yang, H.; Han, P.; Xu, N.; Zhang, Q. Preparation of Dy ${ }^{3+}$-activated strontium orthosilicate $\left(\mathrm{Sr}_{2} \mathrm{SiO}_{4}: \mathrm{Dy}^{3+}\right)$ phosphors and its photoluminescent properties. J. Alloy. Compd. 2012, 512, 5-11. [CrossRef]

26. Liu, Y.L.; Lei, B.F.; Shi, C.S. Luminescent properties of a white afterglow phosphor $\mathrm{CdSiO}_{3}: \mathrm{Dy}^{3+}$. Chem. Mater. 2005, 17, 2108-2113. [CrossRef]

27. Xu, J.Y.; Wang, H.; He, Q.B.; Shen, H.; Shimizu, H.J.; Xiang, W.D. Bridgman growth of $\mathrm{Bi}_{4} \mathrm{Si}_{3} \mathrm{O}_{12}$ scintillation crystals. J. Chin. Ceram. Soc. 2009, 37, 295-298.

28. Zhang, Y.; Xu, J.Y.; He, Q.B.; Lu, B.L. Bridgman growth and characterization of $\mathrm{Bi}_{4}\left(\mathrm{Ge}_{\mathrm{x}} \mathrm{Si}_{1-\mathrm{x}}\right)_{3} \mathrm{O}_{12}$ mixed crystals. J. Cryst. Growth 2013, 362, 121-124. [CrossRef]

29. Zhang, Y.; Xu, J.Y.; Shao, P.F. Growth and spectroscopic properties of Yb:BSO single crystal. J. Cryst. Growth 2011, 318, 920-923. [CrossRef]

30. Yang, B.B.; Xu, J.Y.; Shen, H.; Zhang, Y.; Lu, B.L.; Jiang, G.J. Crystallization behavior of $\mathrm{Bi}_{4} \mathrm{Si}_{3} \mathrm{O}_{12}-\mathrm{Bi}_{4} \mathrm{Ge}_{3} \mathrm{O}_{12}$ pseudo-binary system and its crystal growth. J. Synth. Cryst. 2013, 42, 13-16.

31. Xiong, Z.Y.; Xu, J.Y.; Zhang, Y.; Tan, Z.J. Fluorescence and thermoluminescence of bismuth silicate-germanate [ $\mathrm{Bi}_{4} \mathrm{Si}_{3(1-\mathrm{x})} \mathrm{Ge}_{3 \mathrm{x}} \mathrm{O}_{12}$ ] crystals. Mater. Res. Innov. 2014, 18, S2-294-S2-298. [CrossRef]

32. McCamy, C.S. Correlated color temperature as an explicitfunction of chromaticity coordinates. Color Res. Appl. 1992, 17, 142-144. [CrossRef]

33. Erdem, T.; Nizamoglu, S.; Sun, X.W.; Demir, H.V. A photometric investigation of ultra-efficient LEDs with high color rendering index and high luminous efficacy employing nanocrystal quantum dot luminophores. Opt. Express 2010, 18, 340-347. [CrossRef] [PubMed] 
34. Mishra, L.; Sharma, A.; Vishwakarma, A.K.; Jha, K.; Jayasimhadri, M.; Ratnam, B.V.; Jang, K.; Rao, A.S.; Sinha, R.K. White light emission and color tenability of dysprosium doped barium silicate glasses. J. Lumin. 2016, 169, 121-127. [CrossRef]

35. Fuchs, E.C.; Sommer, C.; Wenzl, F.P.; Bitschnau, B.; Paulitsch, A.H.; Mühlanger, A.; Gatterer, K. Poly spectral white light emission from $\mathrm{Eu}^{3+}, \mathrm{Tb}^{3+}, \mathrm{Dy}^{3+}, \mathrm{Tm}^{3+}$ codoped $\mathrm{GdAl}_{3}\left(\mathrm{BO}_{3}\right)_{4}$ phosphors obtained by combustion synthesis. Mater. Sci. Eng. B 2009, 156, 73-78. [CrossRef]

36. Ci, Z.P.; Sun, Q.S.; Qin, S.C.; Sun, M.X.; Jiang, X.J.; Zhang, X.D.; Wang, Y.H. Warm white light generation from a single phase $\mathrm{Dy}^{3+}$ doped $\mathrm{Mg}_{2} \mathrm{Al}_{4} \mathrm{Si}_{5} \mathrm{O}_{18}$ phosphor for white UV-LEDs. Phys. Chem. Chem. Phys. 2014, 16, 11597-11602. [CrossRef] [PubMed]

37. Rohwer, L.S.; Srivastava, A.M. Development of phosphors for LEDs. Electrochem. Soc. Interface 2003, 12, 36-39.

38. Bachmann, V.M.; Ronda, C.; Meijerink, A. Temperature quenching of yellow $\mathrm{Ce}^{3+}$ luminescence in YAG: Ce. Chem. Mater. 2009, 21, 2077-2084. [CrossRef]

39. Zhu, G.; Ci, Z.P.; Shi, Y.R.; Que, M.D.; Wang, Q.; Wang, Y.H. Synthesis, crystal structure and luminescence characteristics of a novel red phosphor $\mathrm{Ca}_{19} \mathrm{Mg}_{2}\left(\mathrm{PO}_{4}\right)_{14}: \mathrm{Eu}^{3+}$ for light emitting diodes and field emission displays. J. Mater. Chem. 2013, C1, 5960-5969. [CrossRef]

(C) 2017 by the authors. Licensee MDPI, Basel, Switzerland. This article is an open access article distributed under the terms and conditions of the Creative Commons Attribution (CC BY) license (http:/ / creativecommons.org/licenses/by/4.0/). 